\title{
VELHICE FEMININA E ALTERIDADE EM NARRATIVAS ORAIS DA MATINTAPERERA
}

\section{FEMALE OLD AGE AND ALTERITY IN THE ORAL NARRATIVES OF MATINTAPERERA}

\author{
Andressa de Jesus Araújo Ramos ${ }^{1}$, Rubenil da Silva Oliveira ${ }^{2}$, Maria do Perpétuo Socorro \\ Galvão Simões ${ }^{3}$
}

\begin{abstract}
RESUMO: A velhice é, para Boclin (2003), uma categoria que recentemente ganhou maior notoriedade social. Embora muitos pesquisadores tenham estudado essa população, a imagem do velho e, principalmente, da velha sofre preconceitos e estereótipos resultantes da carência de informação e publicação. Contudo, as narrativas orais da Matintaperera, recolhidas pelo "O Imaginário nas Formas Narrativas Orais da Amazônia Paraense" (IFNOPAP) revelaram nova tradução da velhice feminina, não carregada de estereótipos, mas de novidade, contemporaneidade e liberdade. Este artigo tem como objetivo geral compreender a velhice feminina a partir da noção de alteridade em narrativas orais da Matintaperera, recolhidas pelo IFNOPAP. O referencial teórico traz Beauvoir (2018), Goldenberg (2017), Zimerman (2007) e Debert (1994). Portanto, esta pesquisa consiste em revisão bibliográfica e contribuirá aos estudos da velhice, articulada a noção de alteridade, pois assim como Beauvoir (2018) consideramos que a senescência não é uma realidade fixa, mas o produto de um alongamento de um processo.
\end{abstract}

PALAVRAS-CHAVES: velhice; feminino; Matintaperera; narrativas amazônicas orais

\begin{abstract}
For Boclin (2003), old age is a category that has recently gained greater social notoriety. Although many researchers have studied this particular population, the image of the old man and, especially, the old woman suffers prejudices and stereotypes resulting from the lack of information and publications in the area. Nevertheless, the oral narratives of Matintaperera, collected through "The Imaginary in the Oral Narrative Forms of the Paraense Amazon" (IFNOPAP) has revealed a new interpretation of the female old age, not one loaded with stereotypes, but of freshness, contemporaneity and freedom. The general objective of the present article is to understand the female old age from the concept of alterity in the oral narratives of Matintaperera, collected by IFNOPAP. The theoretical framework includes Beauvoir (2018), Goldenberg (2017), Zimerman (2007) and Debert (1994). Thus, this research consists of literature review and will contribute to the studies on old age, articulating the concept of alterity since, just like Beauvoir (2018), we consider senescence not as a fixed reality, but as the product of a process elongation.
\end{abstract}

KEYWORDS: old age; Female; Matintaperera; oral amazonian narratives

\section{Introdução}

\footnotetext{
${ }^{1}$ Doutoranda em Estudos Literários pelo PPG em Letras da UFPA.

${ }^{2}$ Doutor em Letras: Estudos literários pela UFPA. Professor da UFMA.

${ }^{3}$ Doutora em Letras pela UFRJ. Professora da UFPA e do PPG em Letras da UFPA.
} 
Segundo Zimerman (2007), vivemos em uma sociedade, na qual a perspectiva é ser “jovem". Quando uma criança ou um adolescente pensa no futuro se imagina como um jovem, formado em determinada profissão, trabalhando e tendo um bom rendimento econômico. Entretanto, não se vê como um "velho ${ }^{4}$ realizado". Isso acontece porque a imagem do longevo está associada, muitas vezes, à de “[...] um sapato gasto, furado e que, portanto, já não serve mais para nada" (ZIMERMAN, 2007, p. 28). Como se o velho já fosse “[...] um semimorto ou alguém com uma doença infectocontagiosa" (Ibid, 2007, p. 28).

Desse modo, a velhice "aparece como uma espécie de segredo vergonhoso, do qual é indecente falar" (BEAUVOIR, 2018, p. 7), como visto através das metáforas referentes à senescência, "Idoso", "Terceira Idade", "Idade Madura", "Melhor Idade" e "Maturidade". Segundo Neri e Freire (2000), a adoção de tantos termos seria apenas uma forma de soar corretamente, camuflar o preconceito e negar a realidade. Sobre eles, afirma-se:

Deve ter sido um demônio zombeteiro disfarçado de anjo que inventou que a velhice é a "melhor idade". Chamar velhice de "melhor idade" só pode ser gozação, ironia, dizer o contrário do que se quer dar a entender. (...). A coisa mais humilhante da velhice é quando a gente começa a ser tratado como objeto "de respeito" e não como "objeto de desejo". Não quero ser respeitado. Quero ser desejado (ALVES, 2009, p. 53-55).

Além da negação da velhice na sociedade contemporânea, Menezes (2017) salienta que o envelhecimento é também uma questão de gênero, tanto pela ampliação quantitativa de mulheres nessa etapa da vida, quanto por vivenciarem acontecimentos ainda mais complexos pela sua condição de gênero. Dessa maneira, a feminização ou a feminilização da velhice é uma constante que tem se desenvolvido em todo o País, uma vez que:

A classe, o gênero e a raça são influências importantes na experiência do envelhecimento. Por exemplo, o envelhecimento é um fenômeno relacionado ao gênero. As mulheres tendem a viver mais do que os homens, fazendo com que os mais velhos sejam na maioria "mulheres" (GIDDENS, 2005, p. 147).

Para Menezes (2017), por a mortalidade masculina ser maior do que a feminina, a quantidade de mulheres tem ultrapassado a de homens, esse dado revela que a velhice tem se feminilizado. Conforme a Síntese de Indicadores Sociais (SIS), em "Uma análise das condições de vida da população brasileira”, publicado em 2016 pelo IBGE são “(...) 34 mil mulheres acima dos 60 anos, contra 28 mil homens na mesma idade” (MENEZES, 2017, p. 163-164). Contudo, apesar de o número de mulheres ser superior ao de homens, elas

\footnotetext{
${ }^{4}$ Admitimos neste estudo o emprego da palavra "velho (a)" como uma forma de trazer à tona essas vozes silenciadas e reprimidas pela sociedade ao longo dos anos, pois assim como Zimerman (2007) acreditamos que o termo não carrega nada de pejorativo. Pelo contrário: pejorativo é substituir o nome velho por eufemismo, como se ele fosse uma irregularidade a ser escondida. Na realidade, o que precisa ser mudado não é a forma de chamá-lo, mas sim a maneira de tratá-lo.
} 
apresentam, como observa o autor, uma qualidade de vida inferior à do homem, não somente pelos perigos biológicos relacionados ao sexo, mas também por conta das condições sociológicas, trazendo à baila repercussões nos debates por políticas públicas específicas.

Em virtude do quadro de negação da velhice, bem como a sua feminilização este artigo objetiva compreender a velhice feminina a partir da noção de alteridade em narrativas orais da Matintaperera, recolhidas pelo IFNOPAP. Para tanto consideramos os estudos de Beauvoir (2018), Goldenberg (2017), Zimerman (2007) e Debert (1994).

A metodologia deste estudo consistiu em: a) Revisão da Literatura; b) Estudo da história da velhice; c) Estudo da lenda da Matintaperera em textos diversos; d) Leitura das narrativas orais, presentes na coletânea Abaetetuba conta...; e) Seleção das narrativas orais da Matinta que serão analisadas; f) Análise literária das narrativas escolhidas.

Sendo assim, este artigo apresenta três seções. A primeira, Um olhar sobre a velhice discute pesquisas, em nível de Doutorado, sobre a temática do envelhecimento humano e, em seguida, explica nossa preferência pela velhice feminina. Por conseguinte, a segunda, Quem é

a Matintaperera? explica, de forma breve, um dos mitos mais complexos e fascinantes da região norte do país. E, por fim, a terceira, A nova velhice feminina em narrativas orais da Matintaperera apresenta a análise literária de quatro narrativas orais da Matintaperera que revelam uma nova tradução da velhice feminina, articulando-se ao fenômeno da alteridade, que nos possibilita entender a mulher-velha para além de suas representações físicas.

\section{Um olhar sobre a velhice}

Sobre a temática da velhice e/ou do envelhecimento humano encontramos três Teses de Doutorado que apresentam abordagens distintas e ajudarão a entender melhor essa etapa da vida que é repleta de inquietude, fragilidade e angústia. A primeira, intitula-se $O$ idosohomem e o seu envelhecer que foi apresentada ao Programa de Pós-graduação em Serviço Social da Faculdade de História, Direito e Serviço Social da Universidade Estadual Paulista (UNESP), Campus de Franca, em 2001, pela pesquisadora Victalina Maria Pereira di Gianni, nela se analisou o significado do envelhecer para o idoso do sexo masculino e a sua preocupação ou não, em se organizar para a velhice.

Para chegar até o velho, a autora traçou um perfil dos idosos, participantes do projeto de extensão universitária da Universidade Estadual Paulista - UNESP - Campus de Franca, para consequentemente reconhecer as especificidades com que os sujeitos entrevistados por ela expuseram sua concepção sobre a velhice. A constatação da autora foi a de que o envelhecer foi julgado pelos homens como decurso genuíno da vida, manifestado sob distintas 
perspectivas incorporadas de assuntos relevantes os quais permitem revelar toda uma vida entranhada de crenças, regimes, deleites e desilusões. O envelhecer para os entrevistados não indicou uma suspensão do aprender tampouco o impedimento do viver, mas que o velho manifesta “(...) perspectiva de vida mais saudável e com satisfação mais plena de interesses, aspirações, na medida em que a pessoa se prepara para esse envelhecer" (DI GIANNI, 2001, p. 16). Desse modo, a pesquisadora acredita que sua pesquisa abrirá caminhos para uma maior valorização do idoso enquanto homem em busca de sua completa realização humana. Em vista disso, ela concluiu sua Tese com a seguinte frase: "La vecchiaia é bella ancora che brutta" - A velhice é bela ainda que sofrida” (DI GIANNI, 2001, p. 130).

A segunda Tese que tem por título A infância e a velhice: percursos em Manuelzão $e$ Miguilim foi apresentada ao Departamento de Teoria Literária e Literatura Comparada da Faculdade de Filosofia e Ciências Humanas da Universidade de São Paulo em 2010 pela pesquisadora Luciane Marques Ferraz, objetivou estudar características da formação do sujeito nos personagens Manuelzão e Miguilim, em suas vontades e processos identificatórios, nas novelas Campo Geral e Uma estória de amor, ambas do mineiro Guimarães Rosa, considerando os estudos de Freud e Lacan.

Em Campo Geral, Luciane Ferraz examinou o percurso do menino em suas buscas, em sua angustiante passagem do mundo infantil ao mundo adulto, nas fronteiras pouco perceptíveis entre a fantasia e a realidade referente. Em contrapartida, em Uma estória de amor, a pesquisadora observou as linhas narrativa que se justapõem: na primeira, é descrito os preparativos de uma festa em homenagem a mãe falecida, o momento em que os convidados começam a chegar, as histórias que delineiam uma espécie de ritual incipiente da capela fabricada por Manuelzão; na outra, o transcorrer de suas aflições e ideias.

Dessa maneira, Ferraz (2010) concluiu que em ambas as histórias, os processos identificatórios, essenciais para a formação do eu, ligam-se ao modo de descoberta das significações da vida, um dos assuntos principais da obra do autor. O convívio familiar, a imagem da mãe e do pai, as memórias de infância trazidas durante a vida, as correspondências entre o mundo de dentro e o de fora, as significações assimiladas na infância e na senescência são questões que interessam Luciane Ferraz. As noções de sujeito, identificação, desejo, ordem simbólica, condensação e deslocamento, memória e imaginário tão preciosos à psicanálise, serão essenciais para à compreensão dos jogos do inconsciente e a assimilação das particularidades do discurso do sujeito e seus desejos retratados em sua Tese.

Sob outra ótica, Lilian Almeida de Oliveira Lima em sua Tese Meninas, jovens $e$ velhas: personagens tecidas na narrativa de Helena Parenta Cunha, apresentada ao 
Programa de Pós-Graduação da Faculdade de Letras da Pontifícia Universidade Católica do Rio Grande do Sul em Convênio com a Universidade do Estado da Bahia, Doutorado Interinstitucional (DINTER), em 2014 objetivou analisar as personagens femininas presentes na obra ficcional da escritora brasileira Helena Parente Cunha, formada pelos seguintes títulos: Os provisórios (1980), Mulher no espelho (1983), Cem mentiras de verdade (1985), As doze cores do vermelho (1989), A casa e as casas (1996), Vento, ventania, vendaval (1998), Claras manhãs de Barra Clara (2002), Falas e falares (2011).

Com o intuito de responder quem são as figuras femininas parenteanas e quais os seus protótipos comportamentais diante das constituições de gênero e às influências das condições de hegemonia masculina, Lima (2014) estabeleceu diálogo com pesquisadores de distintas áreas do conhecimento, tais como: Teresa de Lauretis e sua concepção de "tecnologia de gênero"; Elaine Showalter e o seu "modelo cultural de escrita das mulheres", o qual apresenta um duplo enunciado, da voz predominante e da voz reprimida; Pierre Bourdieu e as questões sobre o domínio do homem; entre outros.

Para a análise, Lima (2014) reuniu personagens de distintas faixas etárias (infância, adolescência e senescência), uma vez que as demarcações de gênero são dissipadas desde a mais viçosa idade e refletem no decorrer de toda uma existência. Para cada grupo etário, apresenta-se um capítulo, no qual a pesquisadora investiga os sistemas de poder e violência simbólica que meninas, mulheres jovens e maduras e velhas estão sujeitadas, manifestando não apenas o discurso duplo, mas também a aprovação ao poder predominante.

Como vimos, essas Teses fizeram uma abordagem da velhice levando em consideração os ideais de cada área de atuação. A primeira, por exemplo, deu ênfase a velhice masculina, a segunda, por sua vez, analisou o percurso de passagem do tempo da infância a velhice, através da figura de dos personagens masculinos criados por Guimarães Rosa, e por fim, a terceira também investigou a travessia do tempo (infância, juventude e velhice), porém através de personagens femininas. Contudo, até o momento não encontramos nenhuma pesquisa que objetivasse compreender a velhice feminina a partir da noção de alteridade em narrativas orais da Matintaperera, recolhidas pelo IFNOPAP. E é o que propomos em nossa Tese de Doutorado em Letras (Estudos Literários). Dessa maneira, este artigo se trata de resultados parciais de uma pesquisa de doutoramento que está em fase de inicialização.

O estudo da velhice partiu de investigações nos Repositórios Institucionais online das Universidades onde constatamos que são pouquíssimos os trabalhos na área de Letras que se se propõem a compreender essa etapa da vida humana, trabalhos esses tão reduzidos que são possíveis contarmos a dedo e isso acaba nos impedindo de desenvolvermos nossa função 
social, enquanto literários que é o de humanizar os sujeitos através dos textos literários, pois Antônio Candido disse "A literatura desenvolve em nós a quota de humanidade na medida em que nos torna mais compreensivos e abertos para a natureza, a sociedade, o semelhante" (CANDIDO, 1989, p. 117). Verificou-se que a maioria das pesquisas realizadas sobre a velhice se restringem a área da Medicina, da Enfermagem e da Psicologia, oferecendo assim uma visão clínica e não humanitária da senescência. Por conta disso, decidimos estudar a senectude porque acreditamos que:

\begin{abstract}
Os velhos são a nossa história, e nada existe sem uma história anterior. Meu objetivo é fazer com que o velho seja inserido em uma linha humanística, que ele faça parte da linha de vida de toda pessoa. Quero estar junto ao velho, senti-lo, entendê-lo, respeitá-lo, procurar soluções para seus problemas e deixá-lo caminhar conforme pode. Quero ajudar a acabar com os mitos em relação à velhice e estar ao lado do velho em todos os momentos, até seu leito de morte. Convido todos os leitores para fazerem isso junto comigo (ZIMERMAN, 2007, p. 09-10).
\end{abstract}

Dá-se ênfase à velhice feminina, pois “(...) As mulheres na velhice experimentam uma situação de dupla vulnerabilidade com o peso somado de dois tipos de discriminação enquanto mulher enquanto idosa" (DEBERT, 1994, p. 33). Por isso, o estudo sobre a velhice feminina a partir da noção de alteridade possibilitará entender a mulher-velha para além de suas representações físicas, dado que o envelhecer não pressupõe apenas mudanças corporais, mas também psicológicas, sociais, econômicas, políticas e culturais.

Neste sentido, a alteridade é um fenômeno que consiste em "Ser o outro, colocar-se ou constituir-se como outro" (ABBAGNANO, 2007, p.34). O autor explica em seu Dicionário de Filosofia, que esse conceito é mais circunscrito do que diversidade e mais amplo do que diferença, pois a primeira pode apresentar-se como puramente numérica, o que não ocorre com a alteridade. Já a segunda produz a desigualdade, enquanto a alteridade não a implica.

A professora Ellen Spielmann também investiga essa noção tão complexa para muitos, em seu artigo, intitulado “ 'Alteridade': desde Sartre até Bhabha: um surf para a história do conceito" salienta que a alteridade foi abordada no fim dos anos 40 por diversos filósofos, tais como, Jean Paul Sartre, Emmanuel Lévinas e Simone de Beauvoir. Cada um deles abordará de forma diferente o mesmo termo. Sartre, por exemplo, em sua obra $O$ ser e o nada (L'être etneant) (1943) formula conforme Spielmann (2000) uma fenomenologia do outro e da alteridade. Essa fenomenologia firma-se como o marco de uma filosofia existencialista.

Simone Beauvoir em $O$ segundo sexo (1949) defendeu que na alteridade, as mulheres existem como outro, percepção essa que se coaduna com a de Spielmann (2000), as mulheres existem como outro. A feminista foi a pioneira a desaprovar a hierarquização e a obstinação das assimetrias dos gêneros. Conforme as explicações de Spielmann (2000), as mulheres são 
apreendidas como o negativo dos homens, isto é, a carência. Contudo, Beauvoir efetua uma decisiva mudança, em seu tempo, pois para ela "a identidade de gênero não designa um ser substancial, mas sim uma dimensão cultural e histórica” (SPIELMANN, 2000, p.22).

No fim dos anos 1940, a noção de alteridade foi estudada por diversos filósofos. Entretanto, apenas ao final dos anos 1950 que ela ganhou mais força, saindo do âmbito estritamente filosófico e perpassou outras áreas do conhecimento, como a psiquiatria, a antropologia e dentre outras. O psiquiatra e médico da Martinica Frantz Fanon, por exemplo, ampliou a noção de alteridade, até convertê-la, conforme Spielmann (2000), em um modelo analítico da experiência colonial. De fato, Frantz Fanon trouxe e transportou “(...) o conceito às relações entre as raças, à divisão e à assimetria dos gêneros (esboçados e descritos por Simone de Beauvoir)" (SPIELMANN, 2000, p.23).

Claude Lévi-Strauss, de acordo com Bravo (1985), defende que a alteridade é uma das formas dos processos ideológicos da cultura, visto que os processos simbólicos de uma cultura têm "(...) como razão a natureza binária de seus elementos (o cru e o cozido, o proibido e o aceito, o sagrado e o profano)"5 (BRAVO, 1985, p. 16, tradução nossa).

Victor Bravo explica que a literatura é campo fértil para as manifestações da alteridade, pois “A produção literária supõe a encenação da alteridade, através da tentativa de anulação ou de aprofundamento da complexidade que a constitui- a alteridade" (BRAVO, 1985, p. 15, trad. nossa $)^{6}$, em virtude de a cultura ocidental, assim como a cristã procurarem dizimar a alteridade, isso se concretiza como corpo: frente à demonização do corpo existiu a manifestação do divino; frente à invasão do outro passou-se ao sossego do eu; frente a loucura sucedeu-se a razão; frente a sexualidade se colocou as normas das instituições e frente a materialidade de linguagem desenrolou-se a ordem. Por isso, a cultura “(...) para reprimir a manifestação da alteridade, constrói padrões morais, que reprimem os dualismos (o bem frente ao mal, o permitido frente ao proibido)" (BRAVO, 1985, p. 18, tradução nossa ${ }^{7}$ ).

A compreensão acerca a velhice feminina tomando como eixo a noção de alteridade ajuda na ampliação segundo Spielmann (2000) de nosso intelecto e percepção dos fenômenos para além da razão incontestável e limitada, apresentando-se como um plano de estudo que vai além dos nossos limites. Sendo assim, para compreender a velhice feminina a partir da

\footnotetext{
5 “(...) los procesos simbólicos de una cultura tienen como principio la estructura binaria de sus elementos (lo crudo y lo cocido, lo prohibido y lo aceptado, lo sagrado y lo profano)" (BRAVO, 1985, p. 16, tradução nossa). 6 "La producción de lo literario supone la puesta en escena de la alteridad: a través del intento de anulación o de profundización de esa complejidad que lo constituye (la alteridad)" (BRAVO, 1985, p. 15).

7 “(...) para calar las expresior de la alteridade, erige los monumentos de la Moral, esa puesta en escena de la reducción de los dualismos (lo bueno frente a lo malo, lo permitido frente a lo prohibido)" (BRAVO, 1985, p. $18)$.
} 
noção de alteridade escolhemos uma das personagens mais complexas da região norte do país: a famosa Matintaperera, conhecida por ser uma mulher-velha que se transforma em coruja para assombrar as crianças e infernizar os moradores com seu assobio estridente.

\section{Quem é a Matintaperera?}

A Matintaperera é compreendida como uma feiticeira, isto é, "uma bruxa velha que, quando moça, cometeu grandes pecados, e por isso deve cumprir seu fado" (CARVALHO, 2014, p. 225). Conforme a autora, cumprir um fado significa efetivar o seu destino, destino esse que foi estabelecido por intermédio de uma força sobrenatural. Os indivíduos que cumprem um fado são julgados como sujeitos que efetivaram "um pacto com o demônio em troca de alguma vantagem ou vinganças pessoais, recebendo por isso uma punição, como a de se transformarem em animais durante a noite" (CARVALHO, 2014, p. 225).

Na dissertação de Mestrado Imagens da Mitopoética Amazônica: um Memorial das Matinta Pereiras, apresentada ao Programa de Pós-Graduação em Letras da Universidade Federal do Pará (PPGL/UFPA) em 1997, a autora Josebel Akel Fares, amparada em estudos da teoria literária, aproxima a Matinta a uma tradicional bruxa europeia. Para ela, a entidade é "uma bruxa que circula no imaginário popular amazônico e tem ligações com o reino das trevas. É a própria imagem do demônio, alegorizado pelo morcego, ou são pessoas malencaradas, como eufemiza o narrador" (FARES, 1997, p.95). Para Fares (1997), a personagem é "multifacetada" e pode assumir diversas formas, tanto de animais quadrúpedes, quanto ornitomórficos, sendo caracterizada pelas seguintes peculiaridades: o assobio, o fumo e a metamorfose.

$O$ assobio sinaliza a presença da Matinta, que "brinca, ludibria, assobia em cima e embaixo da ladeira, e no meio do mato" (FARES, 1997, p. 37), se um sujeito ouvir o seu canto e lhe oferecer café ou mesmo tabaco, ela aparece, no outro dia, pela manhã, em sua configuração humana, ou seja, desvirada, cobrando o prometido. O fumo, por sua vez, é “(...) um dos responsáveis pelo desmanche da aparição da matinta e incorpora a imagem de vários mitos regionais e universais" (FARES, 1997, p. 67). No Brasil colonial, a ação de fumar era considerada pelos missionários como pecaminosa, portanto, quem fumava sofria severas punições pelas entidades eclesiásticas, sendo o indígena o responsável por mostrar ao caboclo o hábito de “(...) pintar: migar o tabaco, preparar o cigarro de palha ou entupir o cachimbo e tragar para pensar e apreciar a vida no desvaneio" (FARES, 1997, p. 67). Além do assobio e do fumo, a metamorfose também é fundamental para a compreensão da narrativa da Matintaperera, que segundo Fares (1997) pode ser tanto invisível quanto visível. O primeiro 
tipo, conforme a pesquisadora, configura-se como voadora, indefinida, terrena e, por outro lado, o segundo tipo apresenta-se como terrena e voadora.

Sob outro viés, Gisela Macambira Villacorta, apresentou ao Programa de PósGraduação em Antropologia (PPGA/UFPA) no ano de 2000, a Dissertação “As mulheres do pássaro da noite: pajelança e feitiçaria na região do salgado (nordeste do Pará)", que tinha como tema a mulher na pajelança cabocla. A estudiosa procurou, em sua pesquisa, analisar, do ponto de vista antropológico, o papel que é atribuído à figura feminina nesse domínio.

Villacorta (2000) problematiza o fato de a Matintaperera ser sempre uma mulher atípica, fadada a se transformar em entidade. Essa transformação se dá porque a criatura violou a lei ou porque ela praticou o adultério. Dessa maneira, Matintaperera seria um termo nativo usado para nomear a mais perigosa espécie de feiticeira. Contudo, Gisela Villacorta adverte que o homem que se transforma em bicho não recebe essa importância, uma vez que é denominado de "labisônio". Sendo assim, a personagem, no entendimento da autora é concebida, na maioria das vezes, como uma mulher feiticeira que atua e assola os sujeitos sempre, no turno da noite, na companhia de um pássaro, o seu "xerimbabo" homônimo.

Reconhecendo a valiosa contribuição teórica de Fares (1997) e Villacorta (2000), Silva Junior (2014) resolveu, então, apresentar ao Programa de Pós-graduação em Linguagens e Saberes na Amazônia (PPLSA/UFPA) a Dissertação de Mestrado "Representação feminina no mito da Matintaperera em Taperaçu Campo, (Bragança/PA)", que teve como objetivo geral entender como a representação feminina se desenrola nas narrativas orais da matintaperera de Taperaçu Campo (Bragança/PA). Inclusive, ele discute o aspecto da transformação da protagonista em ave (bicho) e a oferta (café, tabaco etc.).

Para explicar a transformação da Matintaperera, Silva Junior (2014) ampara-se em Viveiros de Castro $(2008,2011)$ com a noção de perspectivismo ameríndio, que significa se “(...) colocar no lugar do outro, e esse outro, para os indígenas, são os animais ou os espíritos, ou seja, aqueles que não são humanos" (SILVA JUNIOR, 2014, p.19). Acerca do sacrifício e da dádiva na oferta à ave nortista, Silva Junior (2014) relaciona a promessa feita à Matintaperera, em seis narrativas de moradores de Taperaçu Campo, ao conceito de sacrifício criado pelos antropólogos e sociólogos Marcel Mauss e Henri Hubert (2005) e o de dádiva maussiano (MAUSS, 2003). Desse modo, o pesquisador Silva Junior, em sua Dissertação, direciona a sua discussão à uma matriz/influência indígena desse mito amazônico, refletindo sobre a representação feminina por meio da relação com o outro.

\section{A nova velhice feminina em narrativas orais da Matintaperera}


A maioria das histórias tradicionais da Matintaperera apresentam a velhice feminina de forma preconceituosa e estereotipada, descrevem a mulher-velha como “(...) enrugada, vesga, às vezes, desdentada ou com alguns cacos negros espalhados pela boca babosa, verruga peluda no queixo protuberante ou na ponta do enorme nariz adunco" (SOUZA, 1995, p. 14). Por conta de seu aspecto físico, a Matinta foi, constantemente, associada a uma bruxa europeia, que se trata de uma "mulher muito feia e/ou azeda e mal-humorada" (HOUAISS, 2009, p. 333). Essas características contribuíram para a criação do estereótipo das bruxas que eram representadas por “(...) mulheres de aparência desagradável, com alguma marca de nascença no corpo ou com alguma deficiência física, idosas, mentalmente perturbadas" (VIEIRA, 2007, p. 01-02).

Viana (2013) salienta que para Heinrich Kraemer e James Sprenger, no livro Malleus Maleficarum (O Martelo das Bruxas ou O Martelo das feiticeiras), as bruxas efetivavam um compromisso com o diabo, através do qual renunciavam o catolicismo. Elas se aliavam aos demônios em sabats, orgias e ritos de profanação aos símbolos do cristianismo. Seres diabólicos eram invocados em preces que combinavam frases cristãs com palavras e sinais hereges. Conforme os inquisidores do século $\mathrm{XV}$, as bruxas deliberavam seus sacrilégios através de pacto explícito de lealdade, concebido no coito carnal com os diabos. O voto sacrilégio poderia ser realizado em ritual público ou em qualquer hora em segredo. Em troca de sua alma, as bruxas ganharam poderes que eram usados para causar problemas temporais.

As mulheres, na Idade Média, eram julgadas, conforme Bessa (2006), como representantes ou sacerdotisas do mal. O temor ao feminino originou à caça às bruxas. A caça às bruxas aconteceu devido "ao medo das mudanças, pois a mulher expressa a necessidade de reprodução de toda a sociedade que se sentia ameaçada diante da nova forma de vida que surgia e pelo desejo de se manter as velhas formas" (FREIRE et al, 2006, p. 54). Nesse contexto, especialmente teológico, a "Maldição bíblica da Eva", acompanharia

(...) mais do que nunca a mulher. Estigmatizando-a como responsável pela queda do homem e como tradução da perseguição implacável ao corpo da mulher. A raiz do medo da mulher, no homem, estava ligada aos segredos do parto, da cura e da fabricação de "mezinhas" (termo do qual se originou a palavra medicina). Ela ainda conhecia os segredos dos venenos, das poções e dos filtros (espécie de chá) que enfeitiçavam e matavam, sendo a senhora da vida e da morte. Os homens medievais procuravam lutar contra esse saber-poder, estavam embutidos de crenças e mitos temiam a sabedoria feminina, porque desejavam garantir sua soberania, partindo para uma caçada sangrenta nunca vista em nenhuma outra civilização. O que significa que as fogueiras da Inquisição se constituíram em defesa da sociedade feudal (FREIRE $e t$ al, 2006, p. 54-55). 
Como vimos, a Matintaperera através da imagem de uma mulher-velha foi concebida de forma preconceituosa e estereotipada. Contudo, os resultados de nossas investigações ${ }^{8}$ no acervo do IFNOPAP revelaram uma nova tradução da velhice feminina, que não vem carregada de preconceitos e nem de estereótipos, mas de novidade, contemporaneidade e liberdade, uma vez que as mulheres-velhas descritas nos contos analisados não são assustadoras, nem usam roupas rasgadas e nem realizam o mal, como nas narrativas tradicionais, são sujeitos comuns, como todos nós, capazes de se apaixonar, de encantar as pessoas, sentir desejos e que não vivem isoladas, mas que apreciam o contato com o Outro.

A primeira narrativa que analisamos é "Fiu! Fiu!", narrada por Manoel da Fonseca, na qual ele conta a história de Dona Laura, uma mulher de 70 anos que se transformava em Matintaperera. Diz o conto, que certo dia, ela adoeceu de uma febre muito forte - uma epidemia que estava assolando os moradores da época-, que levou muitos sujeitos à morte e como era costume dos mais antigos socorrer quem estivesse doente, Raimundo resolveu sair do trabalho e ir direto à casa da velha Laura com o intuito de cuidar dela à noite inteira. Então, no meio do caminho algo inusitado aconteceu, ela “(...) Pulou: Pah! E suspendeu a bunda pra cima e a saia, e acendeu a bunda pro lado dele e fez assim: -Fiu, Matintaperera! Aí, ela se endireitou e disse: - Agora vai contar, ouviste?” (SIMÕES E GOLDER, 1995, p. 21).

O segundo conto, "O tabaco da tia", Maria da Fonseca apresenta uma mulher-velha e familiar, a Tia Erinita que segundo a narrativa era muito respeitada pelos sobrinhos e que era acostumada a aparecer em suas casas para pedir tabaco, pois ela chegou dizendo: “- Rai, eu quero... Eu vim aqui pra ti me dar um pouquinho de tabaco, que eu vou pro matapi, e não tenho dinheiro pra comparar tabaco...Tu me dá?” (SIMÕES E GOLDER, 1995, p. 57).

Por outro lado, a terceira narrativa, denominada de "A visita noturna", Sebastiana Rodrigues nos conta a história de uma Matintaperera que assobiava todas as noites e que os moradores locais desejavam muito conhecer a sua forma humana. Por conta disso, Raimundo, certa noite, resolveu levantar-se da rede e gritar: “- Amanhã tu vem buscar cachimbada" (SIMÕES E GOLDER, 1995, p. 160). Feito isso, Joana também decidiu exclamar: “-Amanhã, tu vem buscar uma cachimbada com nós, já ouviste? Que eu quero ver quem és tu" (SIMÕES E GOLDER, 1995, p. 160). Sucedeu que no dia seguinte, pela manhã, alguém bateu na porta e quando abriram estava uma mulher de aproximadamente 50 anos que "Não era gorda. Uma mulher magrinha. Uma mulher bonitinha. E ela veio com um lindo ramo de flor na mão" (SIMÕES E GOLDER, 1995, p. 161) que disse o seguinte: “-Olha, minha filha, eu trouxe

\footnotetext{
${ }^{8}$ Para realizar este artigo lemos os quatro livros do IFNOPAP (Santarém conta..., Belém conta..., Abaetetuba conta... $e$ Bragança conta...). Nesses livros identificamos quatorze narrativas orais da Matintaperera, dentre elas selecionamos quatro que serão analisadas.
} 
este ramos de flor pra ti" (SIMÕES E GOLDER, 1995, p. 161). E ainda disse mais, "Porque tu é menina e tu gosta" (SIMÕES E GOLDER, 1995, p. 162). O curioso desse conto é que além da entidade não possuir uma aparência assustadora e repugnante, ela sabia exatamente o gosto da garota de apenas 13 anos que respondeu com um lindo sorriso no rosto: "a senhora acertou, porque se tiver coisa pra mim gostar é, é, negócio de bicho, pato, galinha. E flor. Eu adoro flor! É só do que eu me vivo" (SIMÕES E GOLDER, 1995, p. 162). A narrativa nos revela que a criança ficou encantada com o ramo de flor que a Matinta lhe deu.

Por fim, o quarto conto é o "Fióte!", narrado por Joana d'Arc que nos revela a história de uma velha, que surgiu no meio do trajeto da viagem de um grupo de músicos a bordo de uma canoa, pedindo carona, os quais atenderam o seu pedido. Entretanto, eles não sabiam que “(...) ela tinha o fado dela e não disse onde ela ia parar” (SIMÕES E GOLDER, 1995, p. 174). Então, eles saíram, foram remando, remando e de repente, "Ela virou a bunda pra cima e deu um assobio. - Fióte! Matintaperera. Ela fez" (SIMÕES E GOLDER, 1995, p. 175).

Como podemos observar, as quatro narrativas orais da Matintaperera nos apresentam uma nova tradução da velhice feminina, que não as colocam como sujeitos repugnantes e assustadores, alusivos às bruxas europeias, mas que podem ser simpáticas, divertidas e encantadoras. Além disso, os contos "Fiu!" e "Fióte!" têm em comum a reflexão sobre a sexualidade feminina, pois neles as velhas não se sentem envergonhas de seus corpos que estão em transformação os escondendo, mas os revelam, comprovando assim que a velhice não interfere na sexualidade, pois foi estabelecido um protótipo de velho e velha como sujeitos assexuados.

De acordo com Salgado (2002), a cultura hispano-americana, principalmente, concebe a sexualidade da mulher-velha como fonte de humor, sendo ridícula e inapropriada. Esse preconceito ocorre, em geral, ao nivelar de forma equivocada a sexualidade feminina a sua capacidade reprodutiva. Essa discriminação para com a mulher velha está intrinsicamente ligada “(...) ao sexismo e é a extensão lógica da insistência de que as mulheres valem na medida em que são atrativas e úteis ao homem" (SALGADO, 2002, p.12). Dentro deste contexto, isto é, no esforço das mulheres de serem belas a aproximação delas com a velhice resulta assustadora e temível, pois elas têm sido "socializadas e treinadas para temer a velhice. Negando o próprio processo de envelhecimento" (SALGADO, 2002, p.12).

Entretanto, Araújo e Carlos (2017) elucidam que a sexualidade não se restringe apenas no ato sexual em si, mas sim de uma combinação de prazer, cumplicidade e amor entre dois indivíduos, como modo de percepção de seu corpo e do outro. Dependendo da maneira como a velhice é vista e das transformações que ela pode sofrer em diversos aspectos da vida, o 
sexo nesse estágio pode sim promover liberdade e assegurar o prazer. Para isso, se faz necessário que o velho ou a velha empregue a sua criatividade para atingir novas maneiras de satisfação. Na realidade, não podemos e nem devemos comparar a velhice de hoje (século $X X I)$ com a dos séculos anteriores, visto que estamos diante de uma nova velha, que não aceita o “o imperativo 'Seja um velho' ou qualquer rótulo que sempre contestaram" (GOLDENBERG, 2017, p. 11). Elas continuam:

(...) cantando, dançando, criando, amando, brincando, trabalhando, transgredindo tabus etc. Não se aposentam de si mesmos, recusaram as regras que os obrigam a se comportar como velhos. Não se tornaram invisíveis, apagados, infelizes, doentes, deprimidos (GOLDENBERG, 2017, p. 11).

Mirian Goldenberg, em seu livro, A Bela Velhice faz referência a essa nova etapa da vida humana que não vem carregada de preconceitos, mas de otimismo, pois segundo ela o velho ou velha de hoje não se trata de um doente, inútil, dependente ou indesejável, é um sujeito que faz parte de:

(...) uma geração que transformou comportamentos e valores de homens e mulheres, que tornou a sexualidade mais livre e prazerosa, que inventou diferentes arranjos amorosos e conjugais, que legitimou novas formas de família e que ampliou as possibilidades de ser mãe, pai, avô e avó (GOLDENBERG, 2017, p. 11-12).

\section{Considerações Finais}

Esta pesquisa objetivou compreender a velhice feminina a partir da noção de alteridade em narrativas orais da Matintaperera, recolhidas pelo IFNOPAP. Para tanto, selecionamos quatro contos dessa entidade, presentes na coletânea Abaetetuba conta... Os resultados permitiram conhecer nova tradução da velhice feminina que não vem carregada de preconceitos e nem de estereótipos, mas de novidade, contemporaneidade e liberdade, pois as senhoras apresentadas nas histórias não seguem um perfil tradicional que definem o velho como "uma pessoa chata, triste, deprimida, cansada, doente e solitária" (ZIMERMAN, 2007, p. 19) ou, então, como "alguém muito vivido, com bastante experiência, mais lento, com doenças, com bastante tempo, tranquilo e mais perto da morte" (Ibid, 2007, p. 19), tratam de velhas poderosas que, como vimos nos contos analisados, não escondem seus corpos envelhecidos, exibem-nos, não são estranhas de nós, familiares, não causam o medo e afastamento, mas encantamento e desejo de nos aproximarmos delas e de tê-las por perto.

Essas características se assemelham a descrição feita por Mirian Goldenberg em sua obra A bela velhice, da "Coroa Poderosa" que se trata de uma mulher madura e independente que "não se preocupa com rugas, celulites, quilos a mais. Ela está se divertindo com tudo o que conquistou com a maturidade: liberdade, segurança, charme, sucesso, reconhecimento, 
respeito, independência" (GOLDENBERG, 2017, p. 23). Essa mulher-velha não quer viver isolada e nem excluída da sociedade, mas deseja sorrir e se comunicar com as pessoas, quer "sair, passear, dançar, viajar, estudar, cuidar da saúde, bem-estar e qualidade de vida, enfim, 'ser ela mesma' e não responder, desesperadamente, às expectativas dos outros" (Ibid, 2017, p. 23). No que se refere ao seu corpo ela quer o exibir "sem medo do olhar dos homens e das mulheres, sem vergonha das imperfeições e sem procurar a aprovação dos outros" (Ibid, 2017, p. 23), pois ela descobriu que a felicidade não está

(...) no corpo perfeito, na família perfeita, no trabalho perfeito, na vida perfeita, mas na possibilidade de "ser ela mesma", exercendo seus desejos, explorando caminhos individuais e tendo a coragem de ser diferente. Ela sabe que não deve jamais se comparar a outras mulheres, porque cada uma é única e especial (Ibid, 2017, p. 23).

Desse modo, a velhice feminina aparece de modo positivo, uma vez que as mulheresvelhas rejeitam os valores culturais depreciativos, pois elas não são concebidas chatas, inconvenientes e rabugentas, mas que podem ser engraçadas, sorridentes e gentis. Não idolatram a juventude, objetivando ser jovens novamente, mas aceitam e valorizam seus corpos envelhecidos os exibindo. Não querem ficar caladas, mas querem se comunicar. Não são sujeitos assexuados, mas tem uma vida sexual ativa.

Esta pesquisa traz contribuições ao estudo da velhice feminina, uma vez que tentamos compreender a mulher-velha para além de suas representações físicas, colocando em foco o fenômeno da alteridade, pois sabemos que as mulheres de idade avançada sofrem, segundo Salgado (2002), diversos obstáculos produzidos por leis e políticas sociais de uma sociedade sexista e gerofóbica. As crenças sexistas e gerofóbicas representam a exaltação da sociedade na produtividade, na atração sexual e no corpo. O cenário social atual prega e conserva a depreciação da mulher-velha, iniciando com a imagem da mulher-velha nas histórias clássicas como bruxas, feias e malvadas e, universalmente, insultada e concebida como um peso. É parcela de uma maioria ignorada cujas carências emocionais, econômicas e físicas continuam, em sua maioria, esquecidas. Nosso objetivo é desconstruir o olhar preconceituoso e estereotipado em relação a mulher-velha, pensando nas suas mudanças não apenas corporais, mas sociais, políticos, econômicos e culturais e como elucida Beauvoir (2018) devemos parar de trapacear, dado que "o sentido de nossa vida está em questão no futuro que nos espera; não sabemos quem somos, se ignorarmos quem seremos: aquele velho, aquela velha, reconheçamo-nos neles" (BEAUVOIR, 2018, p. 11).

\section{REFERÊNCIAS}


ABBAGNANO, Nicola. Dicionário de filosofia. São Paulo: Martins Fontes, 2007.

ALVES, Rubens. Desfiz 75 anos. Campinas: Papirus, 2009.

ARAÚJO, Ludgleydson Fernandes; CARLOS, Karolyna Pessoa Teixeira. Sexualidade na velhice: um estudo sobre o envelhecimento LGBT. Psicología, conocimiento y sociedad, p. 218-237, 2018.

BEAUVOIR, Simone. A velhice. Trad. Maria Helena Franco Martins. 2. ed. Rio de Janeiro: Nova Fronteira, 2018.

BESSA, Daniela Borja. A Batalha Espiritual e o Erotismo. Revista de Estudos da Religião (REVER), № 1, pp. 39-49, 2006.

BOCLIN, Mônica Carvalho Pinto. Tempo, feminino e identidade: a imagem feminina na velhice. 2003. 94 f. Dissertação (Mestrado). Rio de Janeiro: Departamento de Psicologia. Pontifícia Universidade Católica do Rio de Janeiro, 2003.

BRAVO, Víctor. Los poderes de la ficción. Para una interpretación de la Literatura Fantástica. Venezuela, Monte Ávila, 1985.

CANDIDO, Antonio. Direitos Humanos e literatura. In. FESTER, A. C. R. (Org.). Direitos humanos E... São Paulo: Brasiliense, 1989.

CARVALHO, Nazaré Cristina. Caleidoscópio do imaginário ribeirinho amazônico. Revista de Estudo e Pesquisa em Educação, Juiz de Fora, v. 16, n. 2, p. 221, 2014.

CASCUDO, Luís da Câmara. Dicionário do Folclore Brasileiro. 12. ed. São Paulo: Global, 2012.

CONCEIÇÃO, Gilmar Henrique; FREIRE, Mariza Scheffer; SOBRINHO, Vilma Pereira. A Figura feminina no contexto da Inquisição. Educere et Educare, Unioeste, Cascavel, v. n. 01, p. 30-39, 2006.

DEBERT, Guita Grin. Gênero e Envelhecimento: Os Programas para a Terceira Idade e o Movimento dos Aposentados. Revista Estudos Feministas, v. 2, n.3, p. 33-51, 1994.

DI GIANNI, Victalina Maria Pereira. O idoso - homem - e o seu envelhecer. 2001. 147 f. Tese (doutorado). São Paulo, Unesp, Faculdade de História, Direito e Serviço Social, 2001.

FARES, Josebel Akel. Imagens da mitopoética amazônica: um memorial das matintas pereras. 1997. 180 f. Dissertação (Mestrado). Belém: PPGL-UFPA, 1997.

FERRAZ, Luciana M. A infância e a velhice: percursos em Manuelzão e Miguilim. 2010. Tese (Doutorado). São Paulo: Faculdade de Filosofia, Letras e Ciências Humanas, Universidade de São Paulo, 2010. 
GIDDENS, Anthony. Sociologia do Corpo: Saúde, Doença e Envelhecimento. In. Sociologia. Porto Alegre: Artmed, 2005.

GOLDENBERG, Mirian. A bela velhice. 7. ed. Rio de Janeiro: Record, 2017.

HOUAISS, Antônio. Dicionário Houaiss da língua portuguesa. Rio de Janeiro: Objetiva, 2009.

JELIN, Elizabeth. Cidadania e Alteridade: o reconhecimento da pluralidade. Revista do Patrimônio Histórico e Artístico Nacional, n. 24, p. 15-25, Brasília, 1996. Disponível em: < http://portal.iphan.gov.br/uploads/publicacao/RevPat24.pdf>. Acesso em 20 maio de 2020.

LARROSA, Jorge. La experiencia de la lectura: estudios sobre literatura y formación. 2. ed. Barcelona: Laertes, 1996.

LIMA, Lilian Almeida de Oliveira. Meninas, jovens e velhas: personagens tecidas na narrativa de Helena Parente Cunha. 2014. 224 f. Tese (Doutorado em Letras). Porto Alegre: Pontifícia Universidade Católica do Rio Grande do Sul, 2014.

MENEZES, Kelly Maria Gomes. Agora é a minha vez de ir pra escola!: os desafios na educação para mulheres velhas em um Programa de EJA, em Fortaleza - CE. 232f. - Tese (Doutorado). Fortaleza: Universidade Federal do Ceará, Programa de Pós-Graduação em Educação Brasileira, 2017.

NERI, Anita Liberalesso; FREIRE Sueli Aparecida (Org.). E por falar em boa velhice. 1. ed. Vol. 1. Campinas: Papirus, 2000.

SALGADO, Carmen Delia Sánchez. MULHER IDOSA: a feminização da velhice. Estudos Interdisciplinares sobre o Envelhecimento. Porto Alegre, v. 4, pp. 7-19, 2002.

SILVA JÚNIOR, Fernando Alves da. Representação feminina no mito da matintaperera em Taperaçu Campo, Bragança (PA). 2014. 181f. Dissertação (Mestrado). Programa de PósGraduação em Linguagens e Saberes na Amazônia. Bragança: UFPA, 2014.

SIMÕES, Maria do Perpétuo Socorro Galvão; GOLDER, Christophe. (Org.). Abaetetuba conta... Belém: Cejup; Universidade Federal do Pará, 1995.

SPIELMANN, Ellen. Alteridade: desde Sartre até Bhabha: um surf para a história do conceito. Revista Brasileira de Literatura Comparada. Rio de Janeiro: Abralic, 2000.

SOUZA, Laura de Melo e. A feitiçaria na Europa Moderna. 2. ed. São Paulo: Ática, 1995.

VIANA, Geysa Novais. As bruxas no Malleus Maleficarum: caracteres, práticas e poderes demoníacos, 2013. Disponível em: <https://www2.unifap.br/marcospaulo/files/2013/05/ASBRUXAS-NO-MALLEUS-MALEFICARUM.pdf>. Acesso em 10 ago. 2020.

VIEIRA, Bruno César Ferreira. Bruxaria e Feminismo. Uma análise da independência da mulher através dos seriados de TV. In: Anais do XII Seminário Nacional e III Seminário Internacional Mulher e Literatura- Gênero, Identidade e Hibridismo Cultural. Ilhéus, 2007. 
VILLACORTA, Gisela Macambira. "As Mulheres do Pássaro da Noite”: pajelança e feitiçaria na região do salgado (Nordeste do Pará). Dissertação de Mestrado em Antropologia Social. Belém: UFPA, 2000.

ZIMERMAN, Guite I. Velhice: aspectos biopsicossociais. Porto Alegre: Artmed, 2007.

Recebido em 15/05/2020. Aceito em 12/08/2020. 